\title{
Oecologia
}

\section{Consequences of combined herbivore feeding and pathogen infection for fitness of Barbarea vulgaris plants \\ --Manuscript Draft--}

\begin{tabular}{|c|c|}
\hline \multicolumn{2}{|l|}{ Manuscript Number: } \\
\hline Corresponding Author: & $\begin{array}{l}\text { Thure Pavlo Hauser, Ph.D. } \\
\text { DENMARK }\end{array}$ \\
\hline \multirow[t]{5}{*}{ Order of Authors: } & Tamara van Mölken \\
\hline & Vera Kuzina \\
\hline & Karen Rysbjerg Munk \\
\hline & Carl Erik Olsen \\
\hline & Thure Pavlo Hauser, Ph.D. \\
\hline \multirow[t]{2}{*}{ Suggested Reviewers: } & $\begin{array}{l}\text { Arjen Biere } \\
\text { A.Biere@nioo.knaw.nl } \\
\text { One of the few researchers focusing on interactions of plants with both } \\
\text { phytopathogens and arthropod herbivores. Guest editor on the subject in an recent } \\
\text { volume of Funct Ecol }\end{array}$ \\
\hline & $\begin{array}{l}\text { Ayco Tack } \\
\text { ayco.tack@helsinki.fi } \\
\text { another ecologist who has published on three-way interactions }\end{array}$ \\
\hline
\end{tabular}


1 Consequences of herbivore feeding and pathogen infection for fitness of

6 Tamara van Mölken**a ${ }^{\text {a }}$ Vera Kuzina ${ }^{\mathrm{a}}$, Karen Rysbjerg Munk ${ }^{\mathrm{a}}$, Carl Erik Olsen ${ }^{\mathrm{a}}$,

7 Thomas Sundelin ${ }^{\mathrm{a}}$, Nicole M. van $\operatorname{Dam}^{\mathrm{c}}$ \& Thure P. Hauser ${ }^{\mathrm{a}}$.

9 Except for the first and last author, all authors are listed in alphabetical order.

11 a Department of Plant and Environmental Sciences, University of Copenhagen, Frederiksberg,

Denmark

${ }^{\mathrm{c}}$ Department of Ecogenomics, Radboud University Nijmegen, Nijmegen, the Netherlands

14

*Corresponding author: Thure P. Hauser, tpha@life.ku.dk, mobile and sms: +45 20114469 , no fax presently

Declaration of Authorship: TvM and TPH conceived and designed the experiments. TvM advice. 


\section{Abstract}

Plants are often attacked by pathogens and insects. Their combined impact on plant performance and fitness depends on complicated three-way interactions and the plants ability to compensate for resource losses. Here, we evaluate the response of Barbarea vulgaris, a wild crucifer, to combined attack by the oomycete Albugo sp., causing white rust, and a flea beetle, Phyllotreta nemorum. Plants from two B. vulgaris types that differ in resistance to $P$. nemorum were exposed to Albugo and $P$. nemorum alone and in combination, and monitored for pathogen infection, herbivore damage, defence compounds, nutritional quality, biomass and seed production.

Albugo developed strong infections in the insect-resistant plants, whereas insectsusceptible plants were hardly infected. Concentrations of Albugo DNA were higher in plants also exposed to herbivory; likewise, flea beetle larvae caused more damage on Albugoinfected plants. Concentrations of saponins and glucosinolates strongly increased when plants were exposed to $P$. nemorum, when insect-susceptible plants were exposed to Albugo, and sometimes even more in the combined treatment. The biomass of young insect-susceptible plants was lower when exposed to flea beetles, and the number of leaves of both plant types was negatively affected by combined exposure. After flowering, however, adult plants produced similar numbers of viable seeds, irrespective of treatment.

Our study supports that pathogens and herbivores can benefit from each others presence on a host plant and that the plant reacts by inducing specific and general defences. However, plants may be able to compensate for biomass loss of single and combined attacks over time.

Key-words: Albugo sp.; defence reactions, plant vigour; Phyllotreta nemorum; three-way interactions. 


\section{Introduction}

50 Plants are often attacked simultaneously by phytopathogens and insect herbivores, and interactions between them are therefore common (Hatcher 1995; Hauser et al. 2013). The pathogens and insects may interact directly, e.g. if pathogen spores are transported by insects to suitable plant tissues, or indirectly through changes in the plant induced by one antagonist that also affect the other. Thus, pathogen infections can modify attractiveness of the host plant to herbivorous insects (Stout et al. 2006; van Molken et al. 2012) as well as their consumption, growth rate, survival and fitness (Hatcher 1995; Hatcher and Paul 2000; Paul et al. 2000; Rostas and Hilker 2002; Stout et al. 2006; Mouttet et al. 2011; Tack and Dicke 2013).

Indirect interactions between plant antagonists may be caused by defence compounds induced by one antagonist that also affect the other; alternatively, one antagonist may suppress plant defence levels to the benefit of the other. Complex cross-talk between defence signalling pathways in the plant may also contribute to such interactions, as different functional groups of herbivores and pathogens induce different signal pathways that may interfere with each other (Pieterse and Dicke 2007; Koornneef and Pieterse 2008; Thaler et al. 2012). Other causes of interactions may involve changes in resource partitioning or allocation as a consequence of attack (Hatcher 1995). Thus, the combined impact of pathogens and insect herbivores may differ significantly from the sum of impacts of each antagonist on its own (Hatcher 1995; Hauser et al. 2013).

The immediate resource losses incurred by combined attacks by pathogens and herbivores may to some extent be compensated for by re-growth, depending on the amount and distribution of losses, stored resources, integration and mobility among compartments, architecture, and environmental conditions (Paul et al. 2000; Nunez-Farfan et al. 2007; 
pathogen-herbivore interactions translate into effects on plant performance and fitness (Morris et al. 2007; Hauser et al. 2013). Such knowledge is crucial for understanding the evolution of complex plant defences and for integrated pest management.

Here, we analyse interactions between the wild herbaceous crucifer Barbarea vulgaris (Brassicaceae), a flea beetle, and a pathogen. The subspecies ssp. arcuata (Opiz.) Simkovics of Barbarea vulgaris contains two divergent evolutionary types (Agerbirk et al. 2003b; Toneatto et al. 2010; Hauser et al. 2012; Toneatto et al. 2012) that differ in resistance to the flea beetle Phyllotreta nemorum and other important specialist herbivores (Nielsen 1997; Renwick 2002). One plant type is susceptible to all known P. nemorum genotypes and has Pubescent rosette leaves (and therefore designated P-type (Nielsen 1997)), whereas the other is resistant to most genotypes of P. nemorum and has Glabrous leaves (G-type). The two plant types co-exist in Denmark but predominantly in separate populations (Nielsen, unpublished). Barbarea vulgaris is also attacked by an oomycete pathogen Albugo sp. (van Mölken, unpublished). Albugo (as it will be called here) can be observed in natural B. vulgaris populations in Denmark (van Mölken et al., unpublished), has frequently affected our experimental plants at the University, and has been detected in historical herbarium sheets (Choi et al. 2011). The P- and G-type of B. vulgaris have been suggested to differ also in susceptibility to Albugo (Toneatto 2009), based on observations of spontaneously infected plants in a greenhouse.

Possible interactions between B. vulgaris, flea beetles and Albugo could be caused by several different mechanisms. The resistance against flea beetles is caused especially by the saponin hederagenin cellobioside (3-O-cellobiosyl-hederagenin) (Shinoda et al. 2002; Kuzina et al. 2009; Nielsen et al. 2010; Augustin et al. 2011; Augustin et al. 2012), which is present in G-plants from spring to autumn (Agerbirk et al. 2003a). Putative saponins have also been discovered in P-plants (Kuzina et al. 2011), however it is unknown if these have a resistance 
function against any antagonists. Saponins are known to affect many different herbivores and pathogens (Osbourn 1996; Augustin et al. 2011), and Albugo may possibly be sensitive to Ptype saponins. If so, interactions between flea beetles and Albugo could result from increased production of saponins when both are present.

The same mechanism of interaction could potentially arise from induction of glucosinolates. The P-type mainly contains glucosibarin (the optical R-isomer of 2-hydroxy2-phenylethyl-glucosinolate: 2R) whereas the G-type contains glucobarbarin (the optical S isomer: 2S) (Agerbirk et al. 2003a; Agerbirk and Olsen 2011). Glucosinolates are often toxic or deterrent to non-crucifer specialist insects, and play a role in host selection by crucifer specialists (Fahey et al. 2001; Griffiths et al. 2001; Renwick 2002). Glucosinolates may affect fungi and microorganisms (Fahey et al. 2001), including oomycete pathogens (Schlaeppi et al. 2010; Wang et al. 2013), and possibly also Albugo species (Mathur et al. 2013). The strong resistance of G-type plants against flea beetles is not caused by their specific glucosinolates (Agerbirk et al. 2001, 2003b); however, glucosinolates may still affect the flea beetles to a lesser degree.

Albugo infection of B. vulgaris may affect oviposition preference of flea beetles, as has been shown for the specialist herbivorous butterfly Pieris rapae on the related crucifer Lepidium oleraceum (Hasenbank et al. 2011). Albugo sp. is able to suppress defences of Arabidopsis thaliana and Brassica juncea, which enables otherwise incompatible downy mildew strains to infect the plants (Cooper et al. 2008); it is not known if this suppression also affects defence compounds active against herbivores.

Finally, antagonistic interactions may occur in B. vulgaris between the presumed salicylic acid-based signals triggered by the biotroph Albugo and jasmonic acid-based signals triggered by the chewing and mining flea beetles (Pieterse and Dicke 2007; Koornneef and Pieterse 2008; Thaler et al. 2012). However, the specificity of signals in response to these two 
antagonists has never been tested to our knowledge.

Here, we tested whether Albugo infection of the two B. vulgaris plant types modifies their interaction with flea beetles, and vice versa, and whether this leads to interactive impacts on plant growth and reproduction. We experimentally applied Albugo and P. nemorum, alone and in combination, to P- and G-plants in a glasshouse and analysed (i) the degree of herbivory and pathogen infection, (ii) levels of defence related compounds and nutritional quality of the plants, (iii) biomass accumulation and iv) production of viable seeds.

\section{Materials and methods}

\section{Experimental design}

Barbarea vulgaris plants for this experiment originated from a G-type population from Kværkeby and a P-type from Tiss $\varnothing$, both Zealand, Denmark. Both populations are well studied and typical for the two plant types with respect to resistance, saponin and glucosinolate content (Agerbirk et al. 2001; de Jong et al. 2001; Agerbirk et al. 2003b). In March 2010, seeds were sown in a greenhouse with 18 hours light and 6 hours dark. Two hundred seedlings of each plant type were one week later transplanted individually into plastic pots with standard potting soil. Metal halide lamps (Philips HPI-T plus 400W) supplemented daylight, as saponin production in B. vulgaris depends on light quality. When plants were three weeks old and had four to five true leaves, they were transferred to a $15^{\circ} \mathrm{C}$ dark chamber and covered with plastic to keep a high humidity.

Next day, half of the plants were inoculated with Albugo, using a field isolate originating from naturally infected B. vulgaris G-plants from the university campus. A fresh source of inoculum was maintained through serial passage in G-plants. We have never found naturally infected P-plants, and strains adapted to this plant type (if any) thus could not be included. Albugo sporangia were collected by tapping leaves with mature pustules onto a glass slide. 
148 Inoculum was prepared based on a protocol by Dangl et al. (1992): sporangia were hydrated

149 for $90 \mathrm{~min}$ in deionised $\mathrm{H}_{2} \mathrm{O}$ at $15^{\circ} \mathrm{C}$, and adjusted to $7 \times 10^{4}$ sporangia per $\mathrm{ml}$. The plants to

150 be infected by Albugo were inoculated with 5 separate drops of $10 \mu 1$ inoculum on each of

151 their four youngest leaves, and were subsequently kept in plastic bags in darkness at $15{ }^{\circ} \mathrm{C}$.

152 The other half of the plants were given the same treatment, but without sporangia. After three

153 days, all plants were transferred to 18 hours light, 6 hours dark at $17{ }^{\circ} \mathrm{C}$. White rust began to

154 develop ten days post inoculation (dpi); at 14 dpi the number of leaves with rust was counted 155 (Fig 1d).

156 At $17 \mathrm{dpi}$, the plants were divided in two sets with pairwise matching individual sizes,

157 and for infected plants with the same number of leaves with white rust; these sets were used

158 for the first and second harvest, respectively (see below); each set included 66 P- and G-

159 plants. Infected and non-infected plants were further assigned to the flea beetle treatment and

160 a control. Albugo and P. nemorum were thus applied in a fully factorial design with 14

161 replicate plants per plant type, treatment, and harvest. For logistic reasons we did not include

162 a treatment where flea beetles were added before Albugo.

163 All plants were individually covered with mesh bags, and the first portion of flea beetles

164 were added to the assigned plants. The flea beetles were taken from a susceptible line

165 maintained at the university as described by Nielsen (1999). Adults used in our experiment

166 were not older than seven days, and were not sexed before used. A total of nine beetles were

167 added in three portions over 20 days. One month after the first beetles was added (56 dpi),

168 mesh bags and beetles were removed, and the number of leaves counted. At this time, some of

169 the beetles had mated and larval mines were observed in leaves of $91 \%$ of the P-plants.

170 One of the two sets of plants was then used to analyse biomass and chemical composition

171 (first harvest). A leaf disk $(8 \mathrm{~mm} \varnothing)$ from the $5^{\text {th }}$ youngest rosette leaf was frozen in liquid

172 nitrogen, stored at $-70{ }^{\circ} \mathrm{C}$, and used for saponin analysis (see below). Five leaf disks (22-29 
$173 \mathrm{~mm} \emptyset)$ from the $4^{\text {th }}, 8^{\text {th }}$ and $12^{\text {th }}$ youngest and the $4^{\text {th }}$ and $7^{\text {th }}$ oldest leaves were scanned on a

174 flat bed scanner to quantify beetle damage, and analysed for Albugo infection and

175 glucosinolate content; a disk from the $6^{\text {th }}$ youngest leaf was analysed for carbon/nitrogen

176 content (see below). The dry weight of leaves (including leaf disks) and roots were measured

177 separately.

178 The other set of plants (for second harvest) was vernalized at $4{ }^{\circ} \mathrm{C}$ for three months, and

179 transferred to a heated greenhouse with natural light in the beginning of August. When plants

180 had started flowering after 4 weeks, plants from each treatment and plant type were placed in

181 separate mesh tents, and male bumble bees were added as pollinators. A minimum of five

182 bumble bees were present in each tent for one month, at which time flowering had ended.

183 Plants were then transferred to a climate chamber for siliques to ripen.

184 At the second harvest, flowers, siliques, and seeds were dried and counted, and the

185 flowering stalks weighed. Seed germination of 200 seeds per plant was tested on moist filter

186 paper in two Petri dishes per plant at $14 \mathrm{~h}$ light $/ 20^{\circ} \mathrm{C}, 10 \mathrm{~h}$ dark $/ 12{ }^{\circ} \mathrm{C}$. Seeds were considered

187 as germinated if cotyledons emerged within 20 days.

188 Albugo symptoms, infection and herbivore feeding

189 The development of white blister rust was visually estimated at the time of first harvest (56

190 dpi) as the percentage leaf area covered by pustules. Each leaf was assigned to one of five

191 damage categories: 0: no damage; $1: \geq 0-20 \% ; 2: 21-40 \% ; 3: 41-60 \% ; 4: 61-80 \%$; and 5: 81-

$192100 \%$ damage. The total percentage of leaf area with rust was estimated as the sum of the

193 multiplum of the percentage of leaves of each damage class with the mean percentage damage

194 of that class.

195 Albugo infection was estimated by quantitative PCR, using specific primers targeting the 196 internal transcribed spacer (ITS) region (Ac_F2: GCTTCGGCTTGACACATTAG; Ac_R1: 
TCCGTCTCCTTGATGACCTT; Van Mölken et al., in preparation). Briefly, the five dried leaf disks scanned for herbivore consumption (see below) were ground with a mixer mill (Tissuelyser II, Retsch GmbH) and the mix used for DNA and glucosinolate analyses. DNA was extracted with a DNeasy Plant Mini Kit (Qiagen), and quantitative PCR performed on a Mx3000P machine (Stratagene). The PCR reaction was set up in duplicate for each sample using Brilliant II SYBR Green QPCR mastermix (Agilent Technologies) following the manufacturer's instructions. Standards of serially diluted Albugo DNA in water of known concentrations were included. Another standard series was used to estimate the minimum amount of pure Albugo DNA that could be detected. After amplification, a melting curve analysis ensured that only one PCR product was amplified.

$P$. nemorum feeding was estimated as the average percentage of the area of the five leaf discs per plant consumed by adults (holes in leaves) and larvae (leaf-mines), using the software ImageJ (http://rsbweb.nih.gov/ij/).

\section{Plant biochemical composition}

Saponins were extracted from the $5^{\text {th }}$ youngest leaf disk by the methods of Kuzina et al. (2009). They were then analysed by liquid chromatography-mass spectrometry (LC-MS) on an Agilent 1100 Series LC (Agilent Technologies) coupled to a Bruker HCT-Ultra ion trap mass spectrometer (Bruker Daltonics). A Gemini-NX column (Phenomenex; $3 \mu \mathrm{M}, \mathrm{C} 18$, $110 \mathrm{~A}, 2 \times 150 \mathrm{~mm}$ ) was used at a flow rate of $0.2 \mathrm{ml} \cdot \mathrm{min}^{-1}$, proceeded by a SecurityGuard (Phenomenex Gemini-NX C18 4x20 mm). Oven temperature was maintained at $35^{\circ} \mathrm{C}$. The mobile phases were: A: water with $0.02 \%(\mathrm{v} / \mathrm{v})$ trifluoro acetic acid (TFAA); B: acetonitrile with $0.02 \%(\mathrm{v} / \mathrm{v})$ TFAA. The gradient program was: 0 to $1 \mathrm{~min}$, isocratic $12 \% \mathrm{~B} ; 1$ to 33 min, linear gradient 12 to $80 \% \mathrm{~B} ; 33$ to 35 min, linear gradient $80 \%$ to $99 \% \mathrm{~B} ; 35$ to 38 isocratic $99 \% \mathrm{~B} ; 38$ to $45 \mathrm{~min}$, isocratic $12 \% \mathrm{~B}$. The mass spectrometer was run in negative 
electrospray mode, and the mass range m/z 400-1400 acquired.

Five saponins were scored in G-plants: 3-O-cellobiosyl-hederagenin ( $\mathrm{m} / \mathrm{z}$ [M+TFA-] 909, RT 21.5), 3-O-cellobiosyl-oleanoic acid ( $\mathrm{m} / z$ [M+TFA-] 893, RT 24.4), 3-O-cellobiosylgypsogenin ( $\mathrm{m} / \mathrm{z}$ [M+TFA-] 907, RT 22.5), 3-O-cellobiosyl-4-epihederagenin ( $\mathrm{m} / \mathrm{z}$ [M+TFA-] 909, RT 22.6), and 3-O-cellobiosyl-cochalic acid ( $\mathrm{m} / \mathrm{z}$ [M+TFA-] 909, RT 20.7). Three putative saponin compounds were scored in P-plants; these correspond to the putative P-type saponins in Kuzina et al. (2011), based on their mass-to-charge (m/z) ([M+TFAA-]=1073 for saponins 1 (RT 14.8) and 3 (RT 15.5) ; [M+TFAA-]=1159 for saponin 2 (RT 16.2). Peak areas of the saponins were used as estimates of relative saponin content, as exact concentrations could not be determined.

Glucosinolates

Glucosinolates were extracted from 50-100 mg of ground leaf discs (same as used for estimation of herbivore consumption; see above), and analysed as described in van Leur et al. (2008). Additional standards of progoitrin, gluconapin, glucoiberin, glucobrassicanapin, glucotropeaolin, gluconasturtiin, glucoraphanin, glucocoerucin, glucobrassicin, and sinalbin (Phytoplan, Heidelberg, Germany) were used. To calculate concentrations, the glucosinolate measurements were divided by the dry weight of the sample.

Total nitrogen and carbon was measured by mass spectrometry of 3.5 to $4.5 \mathrm{mg}$ of leaf tissue, which was combusted in tin capsules, and analysed with an elemental analyser (20-20; Europa Scientific, Crewe, UK) according to the Dumas method (Schjoerring et al. 1993).

Data analysis

Effects of P. nemorum, Albugo and their combination on the measured traits were analysed by ANOVA (proc GLM); all analyses were done for P- and G-plants separately, due to their difference in resistance to $P$. nemorum. If assumptions of normality and homoscedasticity did 
not hold, data were transformed; otherwise we used GEE analysis (proc GENMOD) after tests

of "Goodness of fit" in GENMOD to determine the appropriate distribution. Seed germination was analysed using events/trials data. Multiple comparisons were tested both in proc GLM (tdiff) and proc GENMOD (diff).

The leaf area with white rust was correlated to Albugo DNA levels (log); this was only done for inoculated G-plants, since P-plants hardly developed rust. Herbivore consumption was only analysed in treatments where flea beetles were applied, and only for P-plants (Gplants are resistant). Some non-inoculated plants developed white rust during the experiment and were excluded from all analyses. All tests were carried out with SAS, version 9.1 (SAS

254 Institute Inc., Cary, USA).

\section{Results}

Albugo and flea beetle interactions

White blister rust developed on only $17 \%$ of the P-plants as compared to $81 \%$ of the Gplants (14 dpi; Fig. 1); a similar difference was found at first harvest (56 dpi; results not 259 shown). Likewise, only very low levels of Albugo DNA were detected in leaf extracts of 260 inoculated P-plants (without flea beetles), while the content in G-plants was much higher 261 (Fig. 2).

262 Extracts of inoculated plants that were also exposed to flea beetles contained more 263 Albugo DNA than inoculated plants without beetles (77 and 2.6 times more DNA in P- and G264 plants, respectively, Fig. 2; Online Resource 1). Inoculated G-plants with flea beetles also 265 developed more rust in younger parts of the plants (results not shown). The leaf area covered 266 with rust was positively correlated with Albugo DNA content in G-plants $(\mathrm{N}=28 ; \mathrm{r}=0.658$; $p=0.0001)$ 
non-inoculated plants (Fig. 2). However, the area consumed by adult flea beetles was not influenced by Albugo infection (Fig. 2, Online Resource 1).

G-plants were highly resistant to flea beetles, as expected, and only 10 out of 25 G-plants had more than $1 \%$ leaf area damaged by adults, and only on old leaves. Only three plants were damaged by larvae, and this never exceeded $0.1 \%$ of leaf area (data not shown).

\section{Biochemical changes in plants}

The content of saponin 1 in P-plants increased with herbivore exposure and with pathogen infection (Fig. 3; Online Resource 1); there was a trend towards an even higher expression in the combined treatment (Table 1). Similar results were obtained for the other saponin compounds produced by P-plants (Table 1).

The resistance-causing saponin of G-plants, hederagenin cellobioside, increased in plants exposed to herbivores and even more in plants exposed also to Albugo (Fig. 3; Online Resource 1). In contrast, this saponin was not affected by pathogen infection alone. Similar results were obtained for the other saponins tested (Table 1; Online Resource 1).

Glucosinolates increased strongly in both P- and G-plants when exposed to flea beetles (Fig. 3). In P-plants there was an additional increase when also exposed to Albugo; in Gplants the glucosinolate concentration was lower in the combined treatment than when only exposed to herbivory (Online Resource 1; Fig. 3). The glucosinolates were not much affected by the pathogen treatment alone.

The carbon-nitrogen ratio of P-plants was negatively affected by flea beetles and decreased by $26 \%$ and $29 \%$ in the herbivore and combined treatments, respectively; this was caused by increased nitrogen concentrations (Table 1); pathogen infection did not affect the carbon-nitrogen ratio. In G-plants, the ratio was positively affected by pathogen infection, due to a decreased nitrogen concentration (Table 1); the other treatments had no effect. 
Plant size after the herbivory and pathogen treatment

294 At the first harvest, herbivory had decreased both the root and shoot biomass of P- and G-

295 plants (Table 1; 28 and 16\% decrease in total weight, respectively), whereas there was no 296 effect of Albugo or any interaction between flea beetles and Albugo (Table 1). Biomass

297 allocation to shoots and roots did not differ between treatments (Table 1).

298 Plants exposed to both flea beetles and Albugo had a lower number of leaves, whereas 299 there was only little, or no, effect of the herbivore and the pathogen on their own (Fig. 3). The 300 reduction in number of leaves for G-plants was significant although the magnitude was small 301 (Table 1; Online Resource 1).

Plant reproduction

303 At the second harvest, the number of flowers, siliques, and seeds did not differ between

304 treatments (Table 1). There was a small positive effect of flea beetles on seed weight of P305 plants, and a slightly negative effect of Albugo on seed weight of G-plants. Seed germination 306 was higher for P-plants exposed to herbivory and for G-plants exposed to the pathogen; in 307 addition, there was a significant interaction between the effects of herbivores and the 308 pathogen in both plant types. However, the number of viable seeds per plant (number of seeds 309 multiplied by germination rate) did not differ between treatments for neither P- or G-plants 310 (Table 1).

\section{Discussion}

312 Our results show that the insect-resistant G-plants of Barbarea vulgaris are much more prone 313 to Albugo sp. infection than the insect-susceptible P-plants. Albugo and flea beetles clearly

314 affect each others performance on the plant, and induce enhanced levels of plant defence

315 compounds in some of the combined treatments. However, plant biomass was affected only 
316 by flea beetles in P-plants, and overall reproduction was not affected by any of the treatments,

317 indicating that plants were able to compensate for resource losses to the pathogen and 318 herbivores.

Different responses to Albugo of the two plant types

320 A difference in susceptibility to Albugo between P- and G-plants was originally suggested by 321 Toneatto (2009), based on spontaneously infected plants in a crossing experiment. Here we 322 found the same difference between plant types: less than $20 \%$ of the P-plants developed white 323 rust and hardly any plants contained Albugo DNA, while more than $80 \%$ of the G-plants 324 developed white rust and contained Albugo DNA. Other inoculation experiments by our group have shown equivalent differences in white rust development, using other P- and Gtype populations of B. vulgaris (Christensen, Heimes, Laybourn, Van Mölken and Hauser, unpublished). Furthermore, we have found white blister rust in natural populations of G328 plants, but never in P-populations (Van Mölken et al., in prep). The difference in susceptibility to Albugo between P-and G-plants thus seems to be associated with the overall divergence between the two plant types of B. vulgaris (Agerbirk et al. 2003a; Hauser et al. 331 2012).

Leaf extracts of a few P-plants contained Albugo DNA but no white rust was observed on the plants. This may be caused by asymptomatic endophytic infections of the plants by Albugo, as suggested by Jacobson et al. (1998) and Ploch and Thines (2011).

Albugo and flea beetles clearly facilitated each other, with more white rust and Albugo DNA

337 in plants also exposed to flea beetles and a higher consumption of larvae in plants also

338 exposed to Albugo. Flea beetles probably spread sporangia among leaves and thereby

339 enhanced dispersal and reinfection. Albugo usually enter the plant via the stomata and has to 
grow actively through plant tissue to spread beyond the point of initial infection. Physical

341 movement of inoculum could thus increase spread and infection success.

342 The higher consumption by larvae in Albugo-infected P-plants, despite the low infection

343 success of Albugo in these plants, could be caused by a lower food quality or palatability that

344 forces larvae to feed more to obtain the necessary nutrients. Especially glucosinolates

345 increased in plants exposed to both P. nemorum and Albugo, and even though the P-type

346 glucosinolates (and saponins) do not confer resistance to the beetles they may decrease

347 digestibility. Alternatively, Albugo could have suppressed unknown defence component that

348 otherwise restricts larval feeding.

349 Changes in plant biochemistry

350 Saponins and glucosinolates were strongly upregulated upon flea beetle attack. Induction of

351 the saponins is new to us, as we have so far considered them to be constitutively produced

352 during the growing season (but see van Leur et al. (2006)). The increased production of

353 hederagenin cellobioside upon flea beetle attack, as well as other G-type saponins, fit their

354 function in resistance against these (Nielsen 1997; Agerbirk et al. 2003a; Kuzina et al. 2009;

355 Kuzina et al. 2011). However, the increased production of saponins by P-plants exposed to

356 flea beetles does not seem adaptive as these saponins clearly do not impede flea-beetle

357 feeding.

358 Saponins were also upregulated by Albugo exposure in P-plants and in the combined

359 treatments of both P- and G- plants (however, only significant in G-plants). As most P-plants

360 did not develop white rust upon Albugo inoculation, this could suggest a role of P-type

361 saponins in resistance. Indeed, some saponins are known to confer resistance against

362 pathogens (Osbourn 1996). Preliminary results, however, suggest that this is not the case

363 (Christensen et al, unpublished). Szakiel et al. (2011) suggested that induction of saponins is 
part of an overall plant defence system, and especially P-type saponins may thus be induced inspecifically by pathogens and herbivores, even by species on which they have no effect.

The strong induction of glucosinolates by flea beetles is in agreement with several other studies (reviewed by Hopkins et al. (2009)); however, another study of B. vulgaris did not find increased concentrations when exposed to the root fly Delia radicum, even though glucosinolates were induced by jasmonic acid application (van Leur et al. 2006; van Leur et al. 2008), and concentrations in Brassica nigra were not increased by the flea beetle $P$. cruciferae (Traw 2002; Traw and Dawson 2002). Glucosinolate induction by herbivores may thus depend on the species pairs involved. However, glucosinolates are not responsible for the strong resistance of B. vulgaris G-plants against flea-beetles (Agerbirk et al. 2003b; Kuzina et al. 2011), suggesting that their induction is triggered as part of a general response to insect damage, as for the saponins.

In P-plants, Albugo induced higher glucosinolate concentrations when together with beetles, but not on its own. Glucosinolates may protect plants against fungal pathogens (Halkier and Gershenzon 2006), but to our knowledge it has not been studied if they also affect oomycetes. The defensive effect of glucosinolates requires cell damage, and Albugo infection may not cause enough damage to trigger this.

In most of the combined treatments the content of saponins and glucosinolates was approximately additive (i.e. equal to the sum of induced concentrations of the single treatments), or perhaps slightly synergistic. This does not support recent hypotheses on 384 antagonistic interactions between different plant defence signalling systems (Koornneef and Pieterse 2008; Thaler et al. 2012). Albugo, as a biotroph pathogen, is expected to trigger a

386 salicylic acid-based defence signalling, which may antagonise the jasmonic acid-based 387 signalling triggered by the cell-damaging flea beetles. Only for glucosinolates in G-plants did 388 we find an antagonistic interaction, where the content of glucobarbarin was significantly 
lower in the combined treatment than in the treatment with only flea beetles. We have no

390 reasonable explanation for why the plant types differ in this respect.

391 Flea-beetles increased the amount of nitrogen relative to carbon in P-plants, but not in G-

392 plants. This was measured as total nitrogen, and may reflect the increase in glucosinolate

393 content when exposed to herbivory. Gomez et al. (2010) have shown that nitrogen may be re-

394 allocated to other parts of the plant upon herbivory as a strategy to preserve nitrogen for re-

395 growth. Whether this was the case for B. vulgaris we cannot determine as roots were not 396 analysed.

397 Plant performance and reproduction

398 Plants that had been exposed to both Albugo and flea beetles had fewer leaves at first harvest 399 than those exposed to only one of them. This may be explained by the increased damage by 400 larvae in Albugo infected plants and the increased Albugo infection in plants with flea beetles. 401 Surprisingly, Albugo has a negative effect on the number of leaves in the P-plants, even 402 though most of these plants are resistant to Albugo (i.e. do not develop white blister rust upon inoculation), but only if the plants were also affected by flea beetles. Similarly, flea beetles 404 decreased biomass also in the flea-beetle resistant G-plants, and had a negative impact on the 405 number of leaves in those plants when together with Albugo. This indicates that even when 406 plants are resistant they have to spend resources on defences (Agrawal et al. 1999), which may otherwise have been used for producing leaves and biomass. Our observation that 408 saponins and glucosinolates were strongly upregulated by flea beetles in both resistant and 409 susceptible plants supports this.

410 At maturity, plants did not differ in reproductive output among the four treatments, 411 despite the differences in pathogen infection, herbivore feeding, leaf number and biomass at 412 first harvest. Likewise, there were no differences in total biomass of the flowering stalks. 
413 Between first and second harvest, plants grew enormously, branched prolifically, and have

414 most likely outgrown the earlier differences. Thus, plasticity in growth-related traits may

415 allow plants to compensate for resource losses from an early attack (Paul et al. 2000; Nunez-

416 Farfan et al. 2007; Fornoni 2011). This is in agreement with recent meta-analyses that

417 pathogens and herbivores can strongly influence each other and the plant parts they attack, but

418 that plant biomass and reproduction is on average less affected by such interactive impacts

419 (Morris et al. 2007; Hauser et al. 2013).

420 Implications

421 A growing number of studies have shown that arthropod herbivores and plant-associated 422 microorganisms can seriously affect each other while on the same plant, either directly or 423 mediated by the plant (Hatcher 1995; Hatcher and Paul 2000; Mouttet et al. 2011; Paul et al. 424 2000; Rostas and Hilker 2002; Stout et al. 2006; Tack and Dicke 2013). Our study shows 425 clear examples this, both for antagonist success and induced changes in the plant that may 426 subsequently affect both (and other) antagonists. However, while these immediate plant427 pathogen-herbivore interactions may be interesting and important, their impact on plant 428 performance, fitness and yield may be strongly moderated by compensatory growth (Fournier 429 et al. 2006; Hauser et al. 2013), as also shown by our results. Unfortunately, very little is 430 known about this; in the meta-analysis of Hauser et al. (2013), only 35 data sets could be 431 found that had estimated combined impacts of herbivores and pathogens on plant 432 performance, despite its clear relevance for ecologists and agronomists alike.

433 An interesting aspect from our study is that plant chemical defences may be upregulated 434 upon combined attack by pathogens and herbivores, even when plants are resistant to one of 435 the antagonists. In B. vulgaris this may be due to the induction of a generalized defence 436 response by both Albugo and flea beetles, but this may however differ among plant species, 
437 specificity of the defence systems, and which antagonist they encounter.

\section{Acknowledgements}

439 We are grateful to the Barbarea group at University of Copenhagen for fruitful discussions

440 and support. We thank L. Munck and E.B. Holub for advice on Albugo inoculation. M-B.

441 Sauer, C. Heimes, S. Christensen and H. Olsen helped with practical work, J.K. Schjoerring

442 and A.H. Ivø with nitrogen analyses, and R.A. de Graaf with glucosinolate analyses. This

443 work was funded by the Danish Agency for Science, Technology and Innovation (grant no.

444 274-08-0462); the authors declare that they have no conflict of interest with this Agency. All

445 experiments comply with current Danish laws.

446 


\section{References}

Agerbirk N, Olsen CE, Nielsen JK (2001) Seasonal variation in leaf glucosinolates and insect resistance in two types of Barbarea vulgaris ssp arcuata. Phytochemistry 58:91-100.

Agerbirk N, Olsen CE, Bibby BM, Frandsen HO, Brown LD, Nielsen JK, Renwick JAA (2003a) A saponin correlated with variable resistance of Barbarea vulgaris to the diamondback moth Plutella xylostella. Journal of Chemical Ecology 29:1417-1433.

Agerbirk N, Ørgaard M, Nielsen JK (2003b) Glucosinolates, flea beetle resistance, and leaf pubescence as taxonomic characters in the genus Barbarea (Brassicaceae). Phytochemistry 63:69-80.

Agerbirk N, Olsen CE (2011) Isoferuloyl derivatives of five seed glucosinolates in the crucifer genus Barbarea. Phytochemistry 72:610-623.

Agrawal AA, Strauss SY, Stout MJ (1999) Costs of induced responses and tolerance to herbivory in male and female fitness components of wild radish. Evolution 53:10931104.

Augustin JM, Kuzina V, Andersen SB, Bak S (2011) Molecular activities, biosynthesis and evolution of triterpenoid saponins. Phytochemistry 72:435-457.

Augustin JM, Drok S, Shinoda T, Sanmiya K, Nielsen JK, Khakimov B, Olsen CE, Hansen EH, Kuzina V, Ekstrøm CT, Hauser T, Bak S (2012) UDP-glycosyltransferases from the UGT73C subfamily in Barbarea vulgaris catalyze sapogenin 3-O-glucosylation in saponin-mediated insect resistance. Plant Physiology 160:1881-1895.

Choi Y-J, Shin H-D, Ploch S, Thines M (2011) Three new phylogenetic lineages are the closest relatives of the widespread species Albugo candida. Fungal Biology 115:598607.

Cooper AJ, Latunde-Dada AO, Woods-Tor A, Lynn J, Lucas JA, Crute IR, Holub EB (2008) Basic compatibility of Albugo candida in Arabidopsis thaliana and Brassica juncea causes broad-spectrum suppression of innate immunity. Molecular Plant-Microbe Interactions 21:745-756.

Dangl J, Holub E, Debener T, Lehnackers H, Ritter C, Crute I, Koncz C, Chua N, Schell J (1992) Genetic definition of loci involved in Arabidopsis-pathogen interactions. In: Koncz CC, N. H.;Schell, J. (ed) Methods in Arabidopsis research. World Scientific Publishing Co, Singapore, pp 393-418

de Jong PW, de Vos H, Nielsen JK (2001) Demic structure and its relation with the distribution of an adaptive trait in Danish flea beetles. Molecular Ecology 10:13231332.

Fahey JW, Zalcmann AT, Talalay P (2001) The chemical diversity and distribution of glucosinolates and isothiocyanates among plants. Phytochemistry 56:5-51.

Fornoni J (2011) Ecological and evolutionary implications of plant tolerance to herbivory. Functional Ecology 25:399-407.

Fournier V, Rosenheim JA, Brodeur J, Diez JM, Johnson MW (2006) Multiple plant exploiters on a shared host: Testing for nonadditive effects on plant performance. Ecological Applications 16:2382-2398.

Gomez S, Ferrieri RA, Schueller M, Orians CM (2010) Methyl jasmonate elicits rapid changes in carbon and nitrogen dynamics in tomato. New Phytologist 188:835-844.

Griffiths DW, Deighton N, Birch ANE, Patrian B, Baur R, Stadler E (2001) Identification of glucosinolates on the leaf surface of plants from the Cruciferae and other closely related species. Phytochemistry 57:693-700.

Halkier BA, Gershenzon J (2006) Biology and biochemistry of glucosinolates. Annual 
Review of Plant Biology, vol 57, pp 303-333

Hasenbank M, Brandon A, Hartley S (2011) White butterfly (Pieris rapae) and the white rust Albugo candida on Cook's scurvy grass (Lepidium oleraceum). New Zealand Journal of Ecology 35:69-75.

Hatcher PE (1995) Three-way interactions between plant-pathogenic fungi, herbivorous insects and their host plants. Biological Reviews 70:639-694.

Hatcher PE, Paul ND (2000) On integrating molecular and ecological studies of plant resistance: variety of mechanisms and breadth of antagonists. Journal of Ecology 88:702-706.

Hauser T, Toneatto F, Nielsen J (2012) Genetic and geographic structure of an insect resistant and a susceptible type of Barbarea vulgaris in western Europe. Evolutionary Ecology 26:611-624.

Hauser TP, Christensen S, Heimes C, Kiær LP (2013) Combined effects of arthropod herbivores and phytopathogens on plant performance. Functional Ecology in press.

Hopkins RJ, van Dam NM, van Loon JJA (2009) Role of glucosinolates in insect-plant relationships and multitrophic interactions. Annual Review of Entomology, vol 54, pp 57-83

Jacobson DJ, LeFebvre SH, Ojerio RS, Berwald N, Heikkinen E, Q1 (1998) Persistent, systemic, asymptomatic infections of Albugo candida, an oomycete parasite, detected in three wild crucifer species. Canadian Journal of Botany-Revue Canadienne De Botanique 76:739-750.

Koornneef A, Pieterse CMJ (2008) Cross talk in defense signaling. Plant Physiology 146:839844.

Kuzina V, Ekstrom CT, Andersen SB, Nielsen JK, Olsen CE, Bak S (2009) Identification of defense compounds in Barbarea vulgaris against the herbivore Phyllotreta nemorum by an ecometabolomic approach. Plant Physiology 151:1977-1990.

Kuzina V, Nielsen JK, Augustin JM, Torp AM, Bak S, Andersen SB (2011) Barbarea vulgaris linkage map and quantitative trait loci for saponins, glucosinolates, hairiness and resistance to the herbivore Phyllotreta nemorum. Phytochemistry 72:188-198.

Mathur P, Sharma E, Singh SD, Bhatnagar AK, Singh VP, Kapoor R (2013) Effect of elevated $\mathrm{CO} 2$ on infection of three foliar diseases in oilseed Brassica juncea. Journal of Plant Pathology 95:135-144.

Morris WF, Hufbauer RA, Agrawal AA, Bever JD, Borowicz VA, Gilbert GS, Maron JL, Mitchell CE, Parker IM, Power AG, Torchin ME, Vazquez DP (2007) Direct and interactive effects of enemies and mutualists on plant performance: A meta-analysis. Ecology 88:1021-1029.

Mouttet R, Bearez P, Thomas C, Desneux N (2011) Phytophagous arthropods and a pathogen sharing a host plant: evidence for indirect plant-mediated interactions. PLoS One 6:e18840.

Nielsen J, Nagao T, Okabe H, Shinoda T (2010) Resistance in the plant, Barbarea vulgaris, and counter-adaptations in flea beetles mediated by saponins. Journal of Chemical Ecology 36:277-285.

Nielsen JK (1997) Variation in defences of the plant Barbarea vulgaris and in counteradaptations by the flea beetle Phyllotreta nemorum. Entomologia Experimentalis et Applicata 82:25-35.

Nielsen JK (1999) Specificity of a Y-linked gene in the flea beetle Phyllotreta nemorum for defences in Barbarea vulgaris. Entomologia Experimentalis et Applicata 91:359-368.

Nunez-Farfan J, Fornoni J, Valverde PL (2007) The evolution of resistance and tolerance to herbivores. Annual Review of Ecology Evolution and Systematics 38:541-566. 
Osbourn A (1996) Saponins and plant defence - A soap story. Trends in Plant Science 1:4-9.

Paul ND, Hatcher PE, Taylor JE (2000) Coping with multiple enemies: an integration of molecular and ecological perspectives. Trends in Plant Science 5:220-225.

Pieterse CMJ, Dicke M (2007) Plant interactions with microbes and insects: from molecular mechanisms to ecology. Trends in Plant Science 12:564-569.

Ploch S, Thines M (2011) Obligate biotrophic pathogens of the genus Albugo are widespread as asymptomatic endophytes in natural populations of Brassicaceae. Mol Ecol 20:3692-3699.

Renwick JAA (2002) The chemical world of crucivores: lures, treats and traps. Entomologia Experimentalis et Applicata 104:35-42.

Rostas M, Hilker M (2002) Asymmetric plant-mediated cross-effects between a herbivorous insect and a phytopathogenic fungus. Agricultural and Forest Entomology 4:223-231.

Schjoerring JK, Kyllingsbaek A, Mortensen JV, ByskovNielsen S (1993) Field investigations of ammonia exchange between barley plants and the atmosphere. 1. Concentration profiles and flux densities of ammonia. Plant Cell Environ. 16:161-167.

Schlaeppi K, Abou-Mansour E, Buchala A, Mauch F (2010) Disease resistance of Arabidopsis to Phytophthora brassicae is established by the sequential action of indole glucosinolates and camalexin. Plant Journal 62:840-851.

Shinoda T, Nagao T, Nakayama M, Serizawa H, Koshioka M, Okabe H, Kawai A (2002) Identification of a triterpenoid saponin from a crucifer, Barbarea vulgaris, as a feeding deterrent to the diamondback moth, Plutella xylostella. Journal of Chemical Ecology 28:587-599.

Stout MJ, Thaler JS, Thomma BPHJ (2006) Plant-mediated interactions between pathogenic microorganisms and herbivorous arthropods. Annual Review of Entomology 51:663689.

Szakiel A, Paczkowski C, Henry M (2011) Influence of environmental biotic factors on the content of saponins in plants. Phytochemistry Reviews 10:493-502.

Tack AJM, Dicke M (2013) Plant pathogens structure arthropod communities across multiple spatial and temporal scales. Functional Ecology 27:633-645.

Thaler JS, Humphrey PT, Whiteman NK (2012) Evolution of jasmonate and salicylate signal crosstalk. Trends in Plant Science 17:260-270.

Toneatto F (2009) Genetics and distribution of insect resistance polymorphism in Barbarea vulgaris. PhD, University of Copenhagen, Frederiksberg

Toneatto F, Nielsen JK, Ørgaard M, Hauser TP (2010) Genetic and sexual separation between insect resistant and susceptible Barbarea vulgaris plants in Denmark. Molecular Ecology 19:3456-3465.

Toneatto F, Hauser TP, Nielsen JK, Ørgaard M (2012) Genetic diversity and similarity in the Barbarea vulgaris complex (Brassicaceae). Nordic Journal of Botany 30:506-512.

Traw MB (2002) Is induction response negatively correlated with constitutive resistance in black mustard? Evolution 56:2196-2205.

Traw MB, Dawson TE (2002) Reduced performance of two specialist herbivores (Lepidoptera : Pieridae, Coleoptera : Chrysomelidae) on new leaves of damaged black mustard plants. Environmental Entomology 31:714-722.

van Leur H, Raaijmakers CE, van Dam NM (2006) A heritable glucosinolate polymorphism within natural populations of Barbarea vulgaris. Phytochemistry 67:1214-1223.

van Leur H, Raaijmakers CE, van Dam NM (2008) Reciprocal interactions between the cabbage root fly (Delia radicum) and two glucosinolate phenotypes of Barbarea vulgaris. Entomologia Experimentalis et Applicata 128:312-322.

van Molken T, de Caluwe H, Hordijk CA, Leon-Reyes A, Snoeren TAL, van Dam NM, 
Stuefer JF (2012) Virus infection decreases the attractiveness of white clover plants for a non-vectoring herbivore. Oecologia 170:433-444.

Wang Y, Bouwmeester K, Van de Mortel JE, Shan WX, Govers F (2013) A novel Arabidopsis-oomycete pathosystem: differential interactions with Phytophthora capsici reveal a role for camalexin, indole glucosinolates and salicylic acid in defence. Plant Cell Environ. 36:1192-1203.

598

599

600 


\section{$601 \quad$ Figure legends}

602 Fig. 1. Species used in this study: (a) Barbarea vulgaris in the rosette and flowering stage.

603 Inserts show a pubescent P-type leaf in the lower left corner and a glabrous G-type leaf in the 604 lower middle part; (b) Phyllotreta nemorum adult (left) and larva (right); (c) white blister rust 605 (pustules) caused by the Albugo sp.; (d) number of P- and G-plants showing symptoms 14 606 days post inoculation.

607

608 Fig. 2. Albugo DNA content and flea beetle damage after infestation with flea beetles (Herb), 609 Albugo (Path) and both (H\&P). Mean values \pm SE are shown for (a) ng Albugo DNA (out of $61010 \mathrm{ng}$ total) in leaves of P- and G-plants; insert shows a DNA melting curve (temperature $\left({ }^{\circ} \mathrm{C}\right)$

611 x fluorescence) demonstrating that only one PCR product was amplified; (b) percentage of 612 leaf area consumed by beetles and larvae in flea beetle susceptible P-plants; G-plants are 613 resistant and not damaged. Columns with different letters of the same case are significantly 614 different at $p<0.05$.

615

616 Fig. 3. Plant traits affected by interactions between flea beetles (Herbivore) and Albugo

617 (Pathogen): (a) saponin content, (b) glucosinolate concentrations (micromoles per gram dry 618 mass); (c) number of leaves; shown for P- and G-plants separately. Columns indicate mean 619 values \pm SE; note that $y$-axes differ. Columns with different letters are significantly different 620 at $p<0.05$. 


\section{Tables}

Table 1. Mean values ( \pm SE) of traits measured on plant of the two plant types in the control, herbivore, pathogen, and combined treatments. Significant differences between a treatment and the control are indicated by bold types; significance levels for interaction terms are indicated by asterisks $((*)$ : $p<0.1 ; *$ : $\mathrm{p}<0.05 ; * *: \mathrm{p}<0.01 ; * * * \mathrm{p}<0.001)$. Results from statistical analyses in Online Resource 1

\begin{tabular}{|c|c|c|c|c|c|c|c|c|}
\hline \multirow[b]{2}{*}{ Traits } & \multicolumn{4}{|c|}{ P-plants } & \multicolumn{4}{|c|}{ G-plants } \\
\hline & Control & Herbivore & Pathogen & Herbivore + pathogen & Control & Herbivore & Pathogen & $\begin{array}{c}\text { Herbivore + } \\
\text { pathogen }\end{array}$ \\
\hline Percentage adult flea beetle damage & & $2.8 \pm 0.6$ & & $3.0 \pm 0.6$ & & & & \\
\hline A. candida DNA (ng) & $0.000 \pm 0.0000$ & $0.000 \pm 0.0001$ & $0.006 \pm 0.0014$ & $0.461 \pm 0.4474$ * & $0.000 \pm 0.0001$ & $0.000 \pm 0.0001$ & $0.626 \pm 0.3518$ & $1.662 \pm 0.6611$ ** \\
\hline Saponin 1 | Hederagenin cellobioside ${ }^{a}$ & $138 \pm 26$ & $278 \pm 46$ & $283 \pm 65$ & $361 \pm 66\left(^{*}\right)$ & $134 \pm 6$ & $183 \pm 8$ & $128 \pm 5$ & $206 \pm 8$ * \\
\hline Saponin 2 | Cochalic acid cellobioside ${ }^{a}$ & $225 \pm 36$ & $403 \pm 52$ & $451 \pm 102$ & $496 \pm 76\left(^{*}\right)$ & $15 \pm 3$ & $50 \pm 7$ & $12 \pm 4$ & $73 \pm 6$ * \\
\hline Glucosinolates $\left(\mu \mathrm{mol} \cdot \mathrm{g}^{-1}\right)^{b}$ & $19 \pm 2$ & $39 \pm 5$ & $26 \pm 3$ & $56 \pm 3$ & $25 \pm 4$ & $56 \pm 3$ & $25 \pm 2$ & $40 \pm 2$ ** \\
\hline Percentage nitrogen & $2.0 \pm 0.2$ & $2.4 \pm 0.2$ & $2.4 \pm 0.3$ & $2.7 \pm 0.2$ & $2.1 \pm 0.1$ & $2.1 \pm 0.2$ & $1.8 \pm 0.2$ & $1.9 \pm 0.1$ \\
\hline Percentage carbon & $42.0 \pm 0.4$ & $40.9 \pm 0.4$ & $43.2 \pm 0.3$ & $41.6 \pm 0.4$ & $42.2 \pm 0.2$ & $42.0 \pm 0.3$ & $42.0 \pm 0.3$ & $42.4 \pm 0.4$ \\
\hline Carbon-nitrogen ratio & $23.5 \pm 1.7$ & $17.5 \pm 1.0$ & $21.6 \pm 2.8$ & $16.6 \pm 1.3$ & $21.4 \pm 1.4$ & $20.8 \pm 1.2$ & $26.1 \pm 2.2$ & $23.5 \pm 1.1$ \\
\hline Root biomass (g) & $1.96 \pm 0.08$ & $1.35 \pm 0.11$ & $2.24 \pm 0.09$ & $1.46 \pm 0.15$ & $1.66 \pm 0.11$ & $1.48 \pm 0.11$ & $1.66 \pm 0.09$ & $1.40 \pm 0.07$ \\
\hline Shoot biomass (g) & $6.32 \pm 0.16$ & $4.55 \pm 0.27$ & $6.81 \pm 0.15$ & $4.53 \pm 0.39$ & $6.61 \pm 0.22$ & $5.90 \pm 0.27$ & $6.88 \pm 0.28$ & $6.05 \pm 0.23$ \\
\hline Root-shoot ratio & $0.31 \pm 0.01$ & $0.29 \pm 0.02$ & $0.33 \pm 0.01$ & $0.32 \pm 0.02$ & $0.25 \pm 0.02$ & $0.25 \pm 0.02$ & $0.24 \pm 0.01$ & $0.23 \pm 0.01$ \\
\hline Total number of flowers & $719 \pm 81$ & $819 \pm 92$ & $803 \pm 77$ & $851 \pm 98$ & $599 \pm 132$ & $676 \pm 113$ & $533 \pm 63$ & $470 \pm 53$ \\
\hline Total number of seed pods & $230 \pm 30$ & $286 \pm 40$ & $278 \pm 26$ & $265 \pm 29$ & $404 \pm 75$ & $379 \pm 63$ & $319 \pm 30$ & $322 \pm 33$ \\
\hline Number of seeds & $1596 \pm 290$ & $1970 \pm 495$ & $2221 \pm 356$ & $1692 \pm 200$ & $4252 \pm 745$ & $3899 \pm 828$ & $3550 \pm 325$ & $3135 \pm 377$ \\
\hline Biomass per seed (mg) & $0.32 \pm 0.02$ & $0.38 \pm 0.02$ & $0.32 \pm 0.02$ & $0.34 \pm 0.03\left(^{*}\right)$ & $0.52 \pm 0.02$ & $0.51 \pm 0.02$ & $0.51 \pm 0.01$ & $0.48 \pm 0.02$ \\
\hline Biomass flowering stalks (g) & $6.4 \pm 0.4$ & $7.1 \pm 0.6$ & $7.0 \pm 0.4$ & $5.8 \pm 0.4$ & $6.5 \pm 0.9$ & $6.9 \pm 0.8$ & $6.1 \pm 0.5$ & $5.5 \pm 0.5$ \\
\hline Seed germination (\%) & $79 \pm 5$ & $87 \pm 3$ & $82 \pm 4$ & $87 \pm 3$ * & $73 \pm 11$ & $66 \pm 7$ & $76 \pm 5$ & $79 \pm 7^{\star \star \star}$ \\
\hline Total number of germinating seeds & $1311 \pm 268$ & $1765 \pm 482$ & $1792 \pm 330$ & $1455 \pm 187$ & $3407 \pm 814$ & $2504 \pm 465$ & $2887 \pm 321$ & $2838 \pm 445$ \\
\hline
\end{tabular}

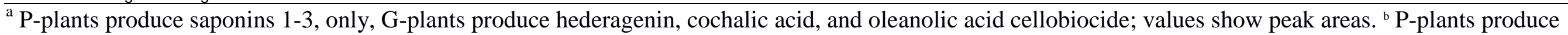
mainly glucosibarin, G-plants glucobarbarin. 
Figs

Figure 1

(a)

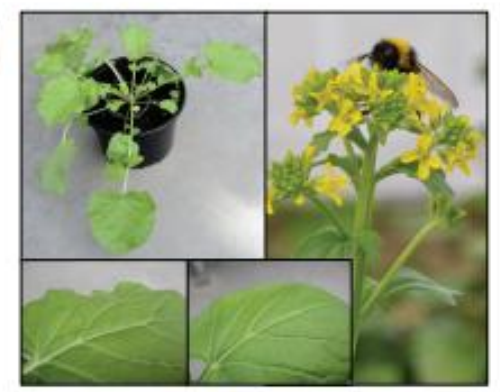

(b)

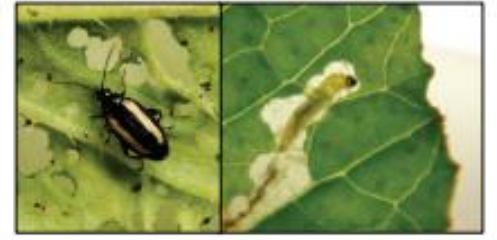

(c)

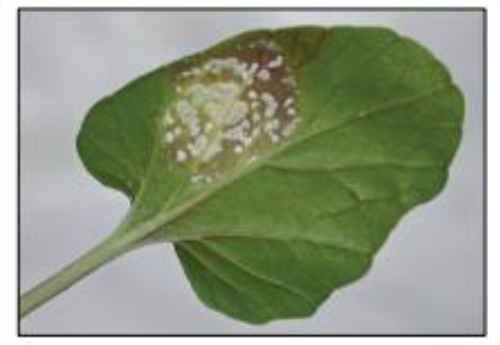

(d)

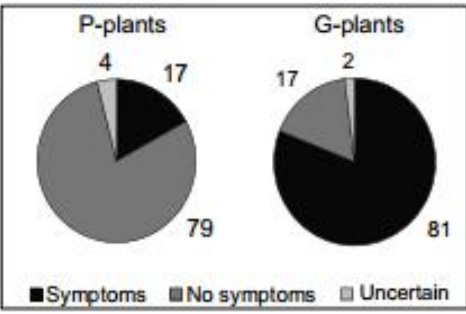


Figure 2
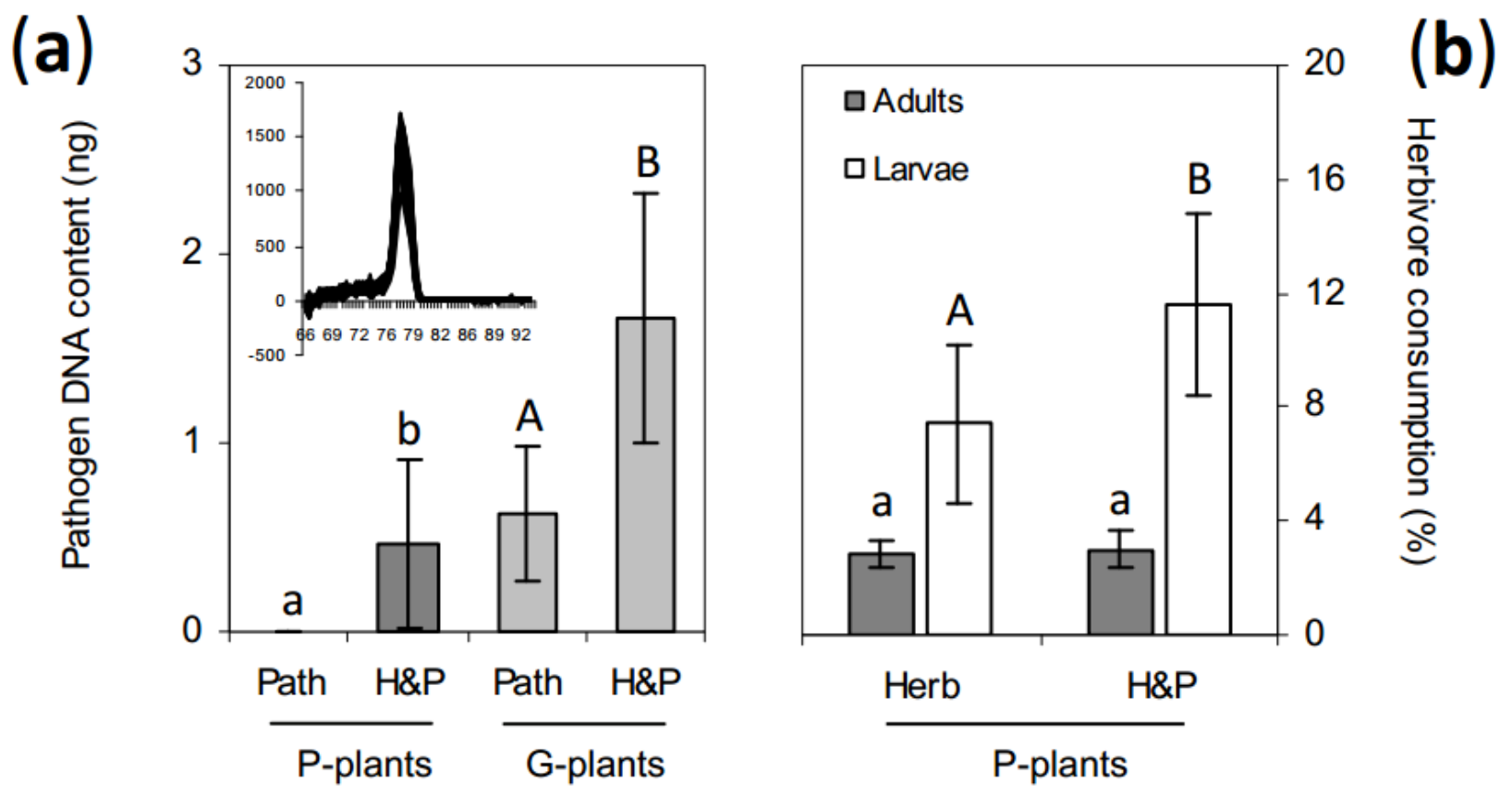
Figure 3

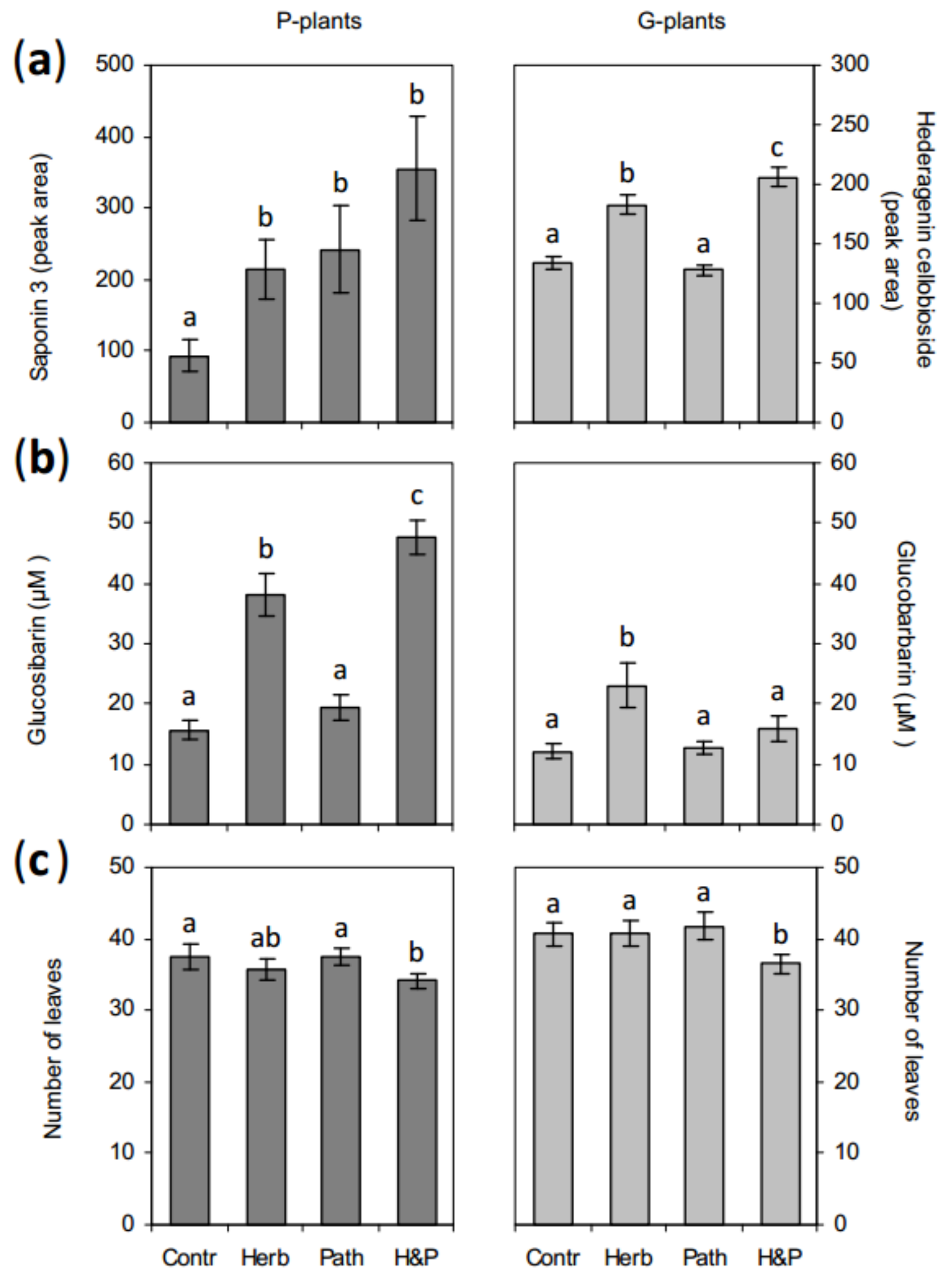


Supplementary Table 1. Statistical analysis (ANOVA: F, or Genmod: $\mathrm{X}^{2}$ ) of the consumption by flea beetles (herbivore), Albugo candida (pathogen) and their combination, and their effects on biochemical, growth, and reproductive traits in P-and G-plants of Barbarea vulgaris. Traits with a mean square for the error term were tested by ANOVA, traits without by proc GENMOD. Significant effects are indicated in bold.

\begin{tabular}{|c|c|c|c|c|c|c|c|c|c|c|c|c|c|c|}
\hline \multirow{2}{*}{$\begin{array}{l}\text { P-plants } \\
\text { Traits }\end{array}$} & \multicolumn{2}{|c|}{ Error } & \multicolumn{4}{|c|}{ Herbivore } & \multicolumn{4}{|c|}{ Pathogen } & \multicolumn{4}{|c|}{ Herbivore $\mathrm{x}$ pathogen } \\
\hline & $\mathrm{df}^{*}$ & $\mathrm{MS}^{\dagger}$ & $\mathrm{df}^{*}$ & $\mathrm{MS}^{\dagger}$ & $\mathrm{F} / \mathrm{X}^{2 \ddagger}$ & $p$ & $\mathrm{df}^{*}$ & $\mathrm{MS}^{\dagger}$ & $F / X^{2 \ddagger}$ & $p$ & $\mathrm{df}^{*}$ & $\mathrm{MS}^{\dagger}$ & $\underset{f}{\mathrm{~F} / \mathrm{X}^{2}}$ & $p$ \\
\hline$\%$ Adult flea beetle consumption & & & & & & & 1 & & 0.00 & 0.9802 & & & & \\
\hline$\%$ Flea beetle larvae consumption & & & & & & & 1 & & 4.54 & 0.0331 & & & & \\
\hline$\%$ Total flea beetle consumption & & & & & & & 1 & & 0.69 & 0.4050 & & & & \\
\hline A. candida DNA & & & 1 & & 7.58 & 0.0059 & & & & & & & & \\
\hline P-type saponin 1 & & & 1 & & 6.36 & 0.0117 & 1 & & 8.65 & 0.0033 & 1 & & 3.65 & 0.0561 \\
\hline P-type saponin 2 & & & 1 & & 4.94 & 0.0262 & 1 & & 7.74 & 0.0054 & 1 & & 3.26 & 0.0711 \\
\hline P-type saponin 3 & & & 1 & & 6.95 & 0.0084 & 1 & & 9.57 & 0.0020 & 1 & & 2.77 & 0.0959 \\
\hline Glucosibarin & & & 1 & & 39.8 & $<0.0001$ & 1 & & 13.71 & 0.0002 & 1 & & 1.75 & 0.1859 \\
\hline$\%$ Nitrogen & 50 & 0.020 & 1 & 0.110 & 5.55 & 0.0224 & 1 & 0.038 & 1.91 & 0.1730 & 1 & 0.004 & 0.20 & 0.6547 \\
\hline$\%$ Carbon & 50 & 1.832 & 1 & 26.74 & 14.6 & 0.0004 & 1 & 12.61 & 6.88 & 0.0115 & 1 & 0.715 & 0.39 & 0.5349 \\
\hline Carbon-nitrogen ratio & 50 & 0.019 & 1 & 0.148 & 7.97 & 0.0068 & 1 & 0.025 & 1.33 & 0.2542 & 1 & 0.003 & 0.16 & 0.6885 \\
\hline Root biomass & 50 & 5.401 & 1 & 223.3 & 41.4 & $<0.0001$ & 1 & 33.85 & 6.27 & 0.0156 & 1 & 7.998 & 1.48 & 0.2294 \\
\hline Shoot biomass & & & 1 & & 41.5 & $<0.0001$ & 1 & & 0.85 & 0.3553 & 1 & & 0.98 & 0.3213 \\
\hline Total biomass & & & 1 & & 42.1 & $<0.0001$ & 1 & & 1.58 & 0.2085 & 1 & & 0.97 & 0.3238 \\
\hline Root-shoot ratio & 50 & 0.003 & 1 & 0.003 & 0.81 & 0.3729 & 1 & 0.006 & 1.74 & 0.1936 & 1 & 0.000 & 0.02 & 0.8753 \\
\hline$\%$ Biomass allocation to shoot & & & 1 & & 0.15 & 0.6938 & 1 & & 0.24 & 0.6222 & 1 & & 0.00 & 0.9606 \\
\hline$\%$ Biomass allocation to roots & & & 1 & & 0.50 & 0.4779 & 1 & & 0.79 & 0.3751 & 1 & & 0.01 & 0.9111 \\
\hline Number of leaves & & & 1 & & 4.86 & 0.0275 & 1 & & 0.43 & 0.5136 & 1 & & 0.63 & 0.4286 \\
\hline Biomass per leaf & 50 & 0.002 & 1 & 0.040 & 26.2 & $<0.0001$ & 1 & 0.001 & 0.36 & 0.5527 & 1 & 0.000 & 0.15 & 0.7004 \\
\hline Total number of flowers & 51 & 108372 & 1 & 85958 & 0.79 & 0.3773 & 1 & 38844 & 0.36 & 0.5520 & 1 & 5914 & 0.05 & 0.8162 \\
\hline Total number of seed pods & 51 & 14185 & 1 & 8096 & 0.57 & 0.4534 & 1 & 1574 & 0.11 & 0.7404 & 1 & 13622 & 0.96 & 0.3317 \\
\hline Total seed weight & & & 1 & & 0.49 & 0.4855 & 1 & & 0.00 & 0.9443 & 1 & & 2.22 & 0.1361 \\
\hline Number of seeds & & & 1 & & 0.00 & 0.9662 & 1 & & 0.10 & 0.7497 & 1 & & 1.37 & 0.2418 \\
\hline Biomass per seed & 51 & 0.006 & 1 & 0.027 & 4.44 & 0.0400 & 1 & 0.009 & 1.41 & 0.2399 & 1 & 0.003 & 0.47 & 0.4942 \\
\hline Biomass flowering stalks & 51 & 2.692 & 1 & 0.206 & 0.08 & 0.7831 & 1 & 3.298 & 1.22 & 0.2736 & 1 & 9.396 & 3.49 & 0.0675 \\
\hline Seed germination & & & 1 & & 70.5 & $<0.0001$ & 1 & & 1.76 & 0.1851 & 1 & & 4.10 & 0.0428 \\
\hline Total number of germinating seeds & & & 1 & & 0.06 & 0.8052 & 1 & & 0.25 & 0.6202 & 1 & & 1.01 & 0.3145 \\
\hline
\end{tabular}




\begin{tabular}{|c|c|c|c|c|c|c|c|c|c|c|c|c|c|c|}
\hline \multirow{2}{*}{$\begin{array}{l}\text { G-plants } \\
\text { Traits }\end{array}$} & \multicolumn{2}{|c|}{ Error } & \multicolumn{4}{|c|}{ Herbivore } & \multicolumn{4}{|c|}{ Pathogen } & \multicolumn{4}{|c|}{ Herbivore $x$ pathogen } \\
\hline & $\mathrm{df}^{*}$ & $\mathrm{MS}^{\dagger}$ & $\mathrm{df}^{\star}$ & $\mathrm{MS}^{\dagger}$ & $F / X^{2} \ddagger$ & $p$ & $\mathrm{df}^{*}$ & $\mathrm{MS}^{\dagger}$ & $F / X^{2 \ddagger}$ & $p$ & $\mathrm{df}^{*}$ & $\mathrm{MS}^{\dagger}$ & $\mathrm{F} / \underset{\ddagger}{\mathrm{X}^{2}}$ & $p$ \\
\hline A. candida DNA & & & 1 & & 6.81 & 0.0091 & & & & & & & & \\
\hline Hederagenin cellobioside & 50 & 561.4 & 1 & 53540 & 95.4 & $<0.0001$ & 1 & 975.6 & 1.74 & 0.1934 & 1 & 2821 & 5.02 & 0.0295 \\
\hline Cochalic acid cellobioside & 50 & 320.7 & 1 & 30462 & 95.0 & $<0.0001$ & 1 & 1375 & 4.29 & 0.0436 & 1 & 2221 & 6.93 & 0.0113 \\
\hline Oleanolic acid cellobioside & 50 & 0.011 & 1 & 1.089 & 103.0 & $<0.0001$ & 1 & 0.021 & 1.95 & 0.1684 & 1 & 0.031 & 2.95 & 0.0923 \\
\hline Gypsegenin cellobioside & 50 & 169.7 & 1 & 11389 & 67.1 & $<0.0001$ & 1 & 48.19 & 0.28 & 0.5964 & 1 & 330.4 & 1.95 & 0.1691 \\
\hline 4-Ephihederagenin cellobioside & 50 & 66.34 & 1 & 6742 & 101.6 & $<0.0001$ & 1 & 191.3 & 2.88 & 0.0957 & 1 & 273.5 & 4.12 & 0.0476 \\
\hline Glucobarbarin & 47 & 62.76 & 1 & 6745 & 107.5 & $<0.0001$ & 1 & 784.5 & 12.5 & 0.0009 & 1 & 753.5 & 12.0 & 0.0011 \\
\hline$\%$ Nitrogen & 50 & 0.013 & 1 & 0.006 & 0.46 & 0.5021 & 1 & 0.059 & 4.59 & 0.0370 & 1 & 0.003 & 0.24 & 0.6234 \\
\hline \% Carbon & 50 & 1.141 & 1 & 0.246 & 0.22 & 0.6444 & 1 & 0.246 & 0.22 & 0.6444 & 1 & 1.380 & 1.21 & 0.2768 \\
\hline Carbon-nitrogen ratio & 50 & 0.012 & 1 & 0.005 & 0.44 & 0.5086 & 1 & 0.061 & 5.30 & 0.0256 & 1 & 0.002 & 0.17 & 0.6851 \\
\hline Root biomass & 50 & 0.251 & 1 & 0.680 & 5.43 & 0.0239 & 1 & 0.022 & 0.17 & 0.6782 & 1 & 0.020 & 0.16 & 0.6902 \\
\hline Shoot biomass & 50 & 0.831 & 1 & 7.835 & 9.42 & 0.0035 & 1 & 0.572 & 0.69 & 0.4108 & 1 & 0.041 & 0.05 & 0.8262 \\
\hline Total biomass & 50 & 1.274 & 1 & 13.13 & 10.3 & 0.0023 & 1 & 0.370 & 0.29 & 0.5921 & 1 & 0.118 & 0.09 & 0.7624 \\
\hline Root-shoot ratio & 50 & 0.004 & 1 & 0.001 & 0.28 & 0.5978 & 1 & 0.006 & 1.38 & 0.2458 & 1 & 0.000 & 0.11 & 0.7441 \\
\hline$\%$ Biomass allocation to shoot & & & 1 & & 0.02 & 0.8746 & 1 & & 0.13 & 0.7226 & 1 & & 0.02 & 0.8856 \\
\hline$\%$ Biomass allocation to roots & & & 1 & & 0.11 & 0.7419 & 1 & & 0.53 & 0.4684 & 1 & & 0.09 & 0.7631 \\
\hline Number of leaves & & & 1 & & 4.66 & 0.0309 & 1 & & 1.84 & 0.1749 & 1 & & 5.16 & 0.0232 \\
\hline Biomass per leaf & 49 & 0.001 & 1 & 0.003 & 4.27 & 0.0440 & 1 & 0.005 & 5.66 & 0.0213 & 1 & 0.001 & 1.75 & 0.1915 \\
\hline Total number of flowers & & & 1 & & 0.00 & 0.9649 & 1 & & 1.00 & 0.3171 & 1 & & 0.58 & 0.4470 \\
\hline Total number of seed pods & 35 & 21862 & 1 & 477.1 & 0.02 & 0.8834 & 1 & 19487 & 0.89 & 0.3516 & 1 & 2819 & 0.13 & 0.7217 \\
\hline Total seed weight & 35 & 0.781 & 1 & 0.562 & 0.72 & 0.4018 & 1 & 1.143 & 1.46 & 0.2343 & 1 & 0.000 & 0.00 & 0.9865 \\
\hline Number of seeds & & & 1 & & 0.29 & 0.5918 & 1 & & 0.82 & 0.3640 & 1 & & 0.00 & 0.9739 \\
\hline Biomass per seed & 35 & 0.003 & 1 & 0.003 & 1.07 & 0.3090 & 1 & 0.013 & 4.27 & 0.0463 & 1 & 0.001 & 0.38 & 0.5430 \\
\hline Biomass flowering stalks & 35 & 4.737 & 1 & 0.089 & 0.02 & 0.8916 & 1 & 1.845 & 0.39 & 0.5366 & 1 & 1.862 & 0.39 & 0.5348 \\
\hline Seed germination & & & 1 & & 1.97 & 0.1604 & 1 & & 52.8 & $<0.0001$ & 1 & & 18.7 & $<0.0001$ \\
\hline Total number of germinating seeds & & & 1 & & 0.76 & 0.3838 & 1 & & 0.01 & 0.9248 & 1 & & 0.55 & 0.4579 \\
\hline
\end{tabular}

Degrees of freedom. † Mean square. $\ddagger$ F-statistics or Chi-square statistics respectively. 